УДК 311. 34; 336

ЕСЕНОВА Валентина Петровна - кандидат юридических наук, доцент; доцент кафедры правоведения Северо-Западного института управления - филиала Российской академии народного хозяйства при Президенте РФ (199178, Россия, г. Санкт-Петербург, Средний пр-кт B.O., 57; VEsenova@ gmail.com)

\title{
ПЕНСИОННОЕ ОБЕСПЕЧЕНИЕ ГРАЖДАН: ПРОБЛЕМНЫЕ ВЕКТОРЫ РЕФОРМИРОВАНИЯ
}

Аннотация. В статье рассматриваются различные проблемные аспекты реформирования пенсионного обеспечения граждан, которые необходимо не только учитывать при осуществлении правового регулирования, но и определять способы их решения. К наиболее острым проблемам следует отнести сохранение и приумножение пенсионных накоплений в период внесения гражданами пенсионных платежей, эффективное управление ими и сокращение необоснованных трат, образование пенсионного надзорного органа, обеспечение достойной жизни пенсионеров, а также создание механизма юридической ответственности за ненадлежащее управление средствами пенсионных фондов либо их существенное уменьшение или обесценивание.

Ключевые слова: пенсионный фонд, риск, пенсионер, пенсионные накопления, управление пенсионным фондом, риск сохранности пенсионных накоплений, юридическая ответственность

$\mathbf{Y}$ величение продолжительности жизни и снижение доли активно занятых граждан трудоспособного возраста по отношению к числу граждан, вышедших на пенсию, по мнению многих участников пенсионных правоотношений в различных государствах ${ }^{1}$, угрожают финансовой устойчивости публичных финансовых систем. Тем не менее такую сложную проблему, как пенсионное обеспечение граждан, нельзя рассматривать только с позиции финансовых и, тем более, предпринимательских интересов публичных или корпоративных участников. К учету и соблюдению прав лиц пенсионного возраста и старше в числе прочего обязывает Конституция РФ, поскольку политика Российской Федерации направлена на создание условий, обеспечивающих достойную жизнь и свободное развитие человека ${ }^{2}$, а также отчисление налогов в течение всей трудовой жизни, включая период осуществления предпринимательской деятельности; включенность граждан в выполнение различных социально значимых или экономических задач государства, включая службу в вооруженных силах государства и многое другое. Исходя из фактической включенности гражданина (на протяжении всей жизни) в развитие государства, обязанность государства по пенсионному обеспечению не уменьшается. Экономическая безопасность, или платежеспособность граждан пенсионного возраста и старше, остается неотъемлемой частью индивидуального благополучия населения. Оно непосредственно связано с выработкой таких экономических и правовых форм, которые способны обеспечить право каждого гражданина на достойную жизнь.

Критериями оценки степени эффективности пенсионного обеспечения в правовом демократическом государстве должны являться:

1 OECD Pensions Outlook 2018. Аналитический доклад Организации по экономическому сотрудничеству и развитию (ОЭСР) «Пенсионный прогноз ОЭСР на 2018 год» (Париж), а также пенсионное регулирование ряда европейских государств. Доступ: https://www.oecd-ilibrary.org/sites/ pens outlook-2018-en/1/2/1/index.html?itemId=/content/publication/pens_outlook-2018-en\&_csp_=c4af 3df621600fc36e971 cfc91971019\&itemIGO=oecd\&itemContentType=book (accessed 13.03.2020).

2 Официальный текст Конституции РФ с внесенными поправками от 21.07.2014 (ч. 1 ст. 7). Доступ: https://base.garant.ru/10103000/ (проверено 13.03.2020). 
- гарантии реализации права каждого гражданина на достаточный уровень пенсионного обеспечения, включающий необходимое питание, одежду и жилище и непрерывное улучшение условий жизни;

- гарантии, при которых государство, гражданин, хозяйствующий субъект, любой собственник должны нести конкретную социальную ответственность.

Социальная справедливость в сфере пенсионного обеспечения реализуется на основе стабильного развития государственной и частной собственности, собственности корпораций и иных юридических лиц, а также путем налогового перераспределения доходов лиц, получающих сверхдоходы, и при осуществлении предпринимательской деятельности, ограничения социального пенсионного обеспечения лиц, чей совокупный месячный доход (заработок) превышает установленный государством размер.

Национальные законодательство и правила могут предусматривать, что пенсионное обеспечение лицу, которое имеет право на него, может быть прекращено или уменьшено, если такое лицо занимается определенной деятельностью по извлечению прибыли или заработок лица превышает установленный законодательством размер. В настоящее время реализация конституционного права граждан на гарантированное социальное обеспечение осуществляется посредством структурного развития национальных пенсионных систем солидарного и несолидарного характера, однако новые формы пенсионных систем не до конца определены. Причинами такой неопределенности являются: старение населения, низкая отдача от пенсионных сбережений и их низкий рост, риск увольнения лиц предпенсионного возраста, нестабильность в сфере трудовой занятости, недостаточное пенсионное обеспечение малообеспеченных групп населения.

Кроме того, увеличение продолжительности жизни стало основанием увеличения пенсионного возраста.

Следовательно, наряду с правовыми, необходимо принимать экономические меры для повышения среднего уровня заработной платы, увеличения ее доли в валовом внутреннем продукте (ВВП), устранения необоснованно высокой дифференциации в оплате труда, используя в т.ч. налоговую систему.

Формирование новой пенсионной системы может предполагать:

- совершенствование пенсионных страховых механизмов, в т.ч. поэтапное дифференцированное увеличение платежей на страховую пенсию (с $6 \%$ до 16-18\% заработной платы) различных категорий плательщиков страховых взносов;

- увеличение уровня пенсионного обеспечения за счет добровольных негосударственных форм пенсионного страхования, как корпоративных (за счет взносов работодателей), так и частных (за счет личных взносов граждан), а также создания правовых механизмов, гарантирующих сохранность страховых взносов и юридическую ответственность государственных и негосударственных пенсионных фондов.

Проблема низких страховых накоплений существует и в европейских странах. По мнению А.А. Ткаченко, экономически развитые страны решают ее иными методами. В январе 2018 г. в Германии для лиц с низкими доходами (менее 2000 евро в месяц) была введена субсидия по дополнительным взносам работодателей (от 240 до 480 евро в год) ${ }^{1}$ в профессиональные пенсионные схемы, т.к. сам работник с такой зарплатой не в состоянии им соответствовать. Но при этом была введена и льгота для работодателей, т.к. $30 \%$ дополнительных взносов вычитаются из выплачиваемого ими налога на заработную плату [Ткаченко 2019: 33].

Изменение структуры пенсионного обеспечения граждан Европейского 
союза и некоторых других государств ${ }^{1}$ позволяет определить направления и риски такого реформирования. Государственные пенсии в ЕС и ряде других стран остаются важным источником пенсионного обеспечения граждан, кроме того, обеспечение малоимущих слоев населения не может быть заменено дополнительными частными формами пенсионного обеспечения.

В некоторых странах нет систем дополнительного пенсионного обеспечения - они обеспечивают валовой коэффициент замешения от 32\% (Польша) до 83\% (Италия). Устойчивость коэффициента замещения зависит от уровня взносов и уровня использования бюджетных средств в компенсировании дефицита между доходами и платежами. А.А. Ткаченко справедливо обращает внимание на то, что коэффициент замещения в России (при среднем уровне зарплаты) значительно ниже, чем в других странах, исключая Германию (по низкой зарплате), где самая высокая зарплата, и Великобританию, по коэффициенту при средней зарплате $(1,0)$ [Ткаченко 2019: 35].

В Испании и Франции государственное пенсионное обеспечение является основным фактором в сглаживании уровней потребления.

В Австралии и Чили для лиц, получающих средний уровень заработной платы, функционируют накопительные системы, финансируемые установленными взносами. (В Чили работники с низкими доходами получают государственные пенсионные пособия из солидарной системы пенсионного обеспечения.)

Дания, Исландия, Израиль и Нидерланды имеют смешанные пенсионные системы с обязательной накопительной частью. Частные добровольные фонды обеспечивают более половины валового коэффициента замещения в Ирландии (18\%) и Великобритании $(20 \%)^{2}$.

В Швейцарии (25\%) государственная система нацелена на замену трети среднего заработка на обязательные накопительные пособия с установленными выплатами для лиц, имеющих средние и высокие заработки (работники, имеющие заработок менее $40 \%$ среднего заработка, не обязаны участвовать в дополнительной системе пенсионного обеспечения).

Общей чертой для всех созданных механизмов является то, что они являются обязательными, поскольку основная ответственность государства связана со сглаживанием уровней потребления в различных социальных группах.

Новая модель пенсионной системы должна обеспечить достижение следующих целей:

- сокращение бедности;

- сокращение демографических рисков посредством выработки мер финансово-экономического характера;

- уменьшение социальных рисков посредством выработки мер правового и экономического характера, способствующих устойчивости трудоустройства и трудовых отношений и сглаживанию потребительской способности граждан;

- перераспределение платежей системы пенсионного обеспечения в отношении лиц, осуществляющих предпринимательскую деятельность свыше 10 лет, включая ограничение (или дифференциацию) выплат страховой части пенсионного обеспечения лицам, чей совокупный месячный доход (заработок) превышает установленный государством размер;

- увеличение участия граждан в пенсионном обеспечении как в качестве получателей пенсии, так и в качестве инвесторов.

В ходе реформирования пенсионных систем необходимо решить такие задачи, как:

\footnotetext{
${ }_{1}$ OECD Pensions Outlook 2018.

2 Там же.
} 
- повышение доверия граждан к создаваемым пенсионным системам;

- повышение доверия граждан к получению достаточного пенсионного обеспечения при достижении ими пенсионного возраста;

- повышение уровня пенсионного обеспечения малоимущих групп населения;

- стабильность трудовой занятости населения;

- обеспечение гарантированной сохранности пенсионных накоплений;

- повышение доходности пенсионных накоплений;

- рост пенсионных накоплений;

- установление гражданам и юридическим лицам налоговых преимуществ для стимулирования создания сбережений на пенсию;

- сохранение справедливости между поколениями и внутри поколений: выгоды одной группы не должны поддерживаться за счет другой группы;

- установление мер правового регулирования, исключающих заинтересованность органов управления юридических лиц и личную заинтересованность их руководителей в управляемых ими пенсионных накоплениях.

В структуру новой пенсионной системы могут входить: государственные пенсионные фонды (ПФ), негосударственные пенсионные фонды (НПФ), резервные фонды (РФ), суверенные фонды (СФ).

Финансирование государственных пенсионных фондов осуществляется за счет бюджетов государств или целевых сборов; негосударственные пенсионные фонды могут финансироваться через ПФ, договоры пенсионного страхования (за счет индивидуальных взносов и накопленных активов). Выплаты пенсий могут зависеть от суммы накопленных активов с установленными взносами или быть определены как установленные выплаты (присуще государственным пенсиям). Бюджет резервных фондов формируется за счет отчислений из чистой годовой прибыли; бюджет суверенных фондов (фондов национального благосостояния) - за счет дополнительных доходов государственного бюджета от нефтегазового комплекса и доходов от управления собственными средствами; часть средств может быть предоставлена в иностранной валюте, которая может инвестироваться в иностранные финансовые активы и др.

В Глобальный государственный пенсионный фонд (Government Pension Fund Global), например, перечисляются сверхдоходы от нефтяной промышленности Норвегии, он управляется подразделением Банка Норвегии (Norges Bank Investment Managevent), которое подчиняется Министерству финансов. Фонд вкладывается только в зарубежные активы: акции, облигации (включая российские облигации федерального займа - ОФ3) и недвижимость. Другой Government Pension Fund Norway - формируется за счет инвестиций в норвежский бизнес. На 2017 г. активы фонда превысили 1 трлн долл.

Законодательство государства может предусматривать образование автономных пенсионных фондов с установлением количественных ограничений портфеля (минимум и максимум пенсионных средств).

Учитывая, что пенсионные фонды не контролируют и не гарантируют прибыль, эффективность управления пенсионными накоплениями следует оценивать не на момент объявления пенсионными фондами о своей доходности в текущий период времени, а на момент получения денег, т.е. когда гражданин уходит на пенсию. Новации, направленные на повышение устойчивости пенсионных систем в свете увеличения продолжительности жизни, должны учитывать интересы разных социально-экономических и гендерных групп, а также последствия таких изменений.

Много вопросов оставляет и определение размера прожиточного минимума пенсионера (ПМП). В настоящее время он определяется уровнем потребитель- 
ских цен на продукты питания, непродовольственные товары и услуги, а также уровнем расходов по обязательным платежам и сборам. Однако в западном правовом порядке есть примеры включения в ПМП уровня цен на наем жилья для пенсионеров (после достижения ими 70 лет) и не имеющих или утративших жилые помещения для проживания, что также представляется целесообразным на рубеже третьего десятилетия XXI в.

Представляется, что принятие унифицированного государственного социального стандарта будет способствовать повышению доверия граждан к параметрам пенсионной реформы и выработке справедливых механизмов по улучшению качества жизни пенсионеров.

Введение дополнительных пенсий направлено на уменьшение бюджетной нагрузки и повышение общего размера пенсионного обеспечения граждан. Как правило, дополнительные пенсии принимают форму накопительных пенсий с установленными взносами, управляются они частными юридическими лицами или пенсионными фондами, включая негосударственные. К пенсионным типам выплат относятся обязательный, добровольный, профессиональный и личный.

Различные формы пенсионных накоплений могут использоваться в борьбе с нищетой в пожилом возрасте. Защита граждан от бедности после окончания трудовой деятельности по возрасту должна оставаться обязанностью государства. Обязательное пенсионное обеспечение имеет большое значение в части максимального охвата будущих пенсионеров, включая низкооплачиваемые группы граждан, граждан, работающих неполный рабочий день, а также работающих не по найму (самозанятых).

Частные типы пенсионных выплат должны быть ориентированы на работников, осуществляющих трудовую деятельность по найму, занятых полный рабочий день и получающих необходимый уровень заработка. Правовые, финансовые и инвестиционные формы аккумулирования частных пенсионных накоплений должны быть понятны для работников, они должны иметь свободный доступ к получению полной информации об организации и деятельности, отчетам по итогам финансового года и результатам годовых аудиторских проверок.

Для сохранения баланса между вносимыми взносами и получаемыми пенсионными выплатами законодательно могут быть установлены минимальный и максимальный размер взносов, имеющий пропорциональное значение к выплатам, ставкам начисления и индексации. Доход, который откладывается, не должен терять свою стоимость с течением времени, поэтому он должен либо получать права на будущую реальную покупательную способность, либо инвестироваться в активы, которые будут увеличиваться в стоимости. Разработка такого механизма должна являться обязанностью государства.

Риск того, что накопленные активы, пенсионные выплаты и доходы могут оказаться в будущем недостаточными, необходимо учитывать и контролировать. При этом под риском следует понимать событие или действие в будущем, которое может неблагоприятно отразиться на достижении финансовых целей при совершении операций по инвестированию средств пенсионных накоплений. Механизм такого контроля, объект, субъект и основания ответственности должны быть установлены государством. Риск наступления неблагоприятных последствий несет государство, работодатель, иное частное юридическое лицо, а также работник. Государственные (страховые) пенсии и коллективные пенсионные системы имеют более широкие возможности для объединения рисков и распределения бремени, но также уязвимы в случае более низких взносов, более низкой доходности активов и более высоких требований получателей пенсий. Гарантией от риска бедности в старости является универсальная базовая государственная пенсия. 
Работник также несет риски - это, прежде всего, способность вносить вклад в государственные и частные пенсионные системы (потеря работы и неблагоприятные схемы выплаты заработка могут оказать влияние на объем пенсионных прав или скорость накопления пенсионных активов, а значит и на уровень получаемых пенсионных доходов), а также риск способности пенсионных взносов адекватно финансировать выход на пенсию.

Высокий размер выплат должен быть обусловлен достаточным размером активов пенсионного фонда и вносимых работниками взносов. Рост минимального размера страховых пенсий и минимальный размер взносов в добровольном пенсионном обеспечении, а также размер максимальной пенсии и размер максимального взноса должны быть сбалансированы законодательством государства, поскольку размер максимальной страховой пенсии может не успевать за ростом максимального взноса, а также целях уменьшения поляризации уровня жизни граждан с минимальными и высокими заработками.

Самостоятельную группу рисков составляют риски, сопряженные с деятельностью пенсионных фондов. Риск высокого уровня операционных расходов (это административные расходы и затраты на управление инвестициями) связан с общим управлением пенсионными фондами. И это при том, что эффективность пенсионных фондов можно оценить исходя из понесенных затрат ${ }^{1}$ по отношению к активам фонда. Чрезмерные эксплуатационные и управленческие расходы или плохо разработанные инвестиционные проекты с пенсионными средствами непосредственно влияют на размер активов накопительной системы, ее доходность и могут в последующем привести к банкротству.

В международной практике пенсионного обеспечения с 2015 по 2019 г. приобрели особое значение проблемы защиты и надзора за администрированием пенсионных накоплений. С 2004 г. в странах ЕС действует независимая Международная организация пенсионного надзора (IOPS), которая осуществляет надзор за частными пенсионными соглашениями и пенсионными выплатами государственного сегмента пенсионной системы.

В целях развития и защиты дополнительных форм пенсионного обеспечения целесообразно принять нормативные правовые акты, регулирующие порядок образования, деятельности и полномочий организаций пенсионного надзора $(\mathrm{OПН),} \mathrm{которые} \mathrm{бы} \mathrm{осуществляли} \mathrm{в} \mathrm{т.ч.} \mathrm{оценку} \mathrm{инвестиционного} \mathrm{риска,} \mathrm{риска}$ финансирования, доходности и сохранности пенсионных накоплений, контроль операционного риска (включая аутсорсинг); проверку эффективности частных пенсионных систем; разработку новых принципов кибербезопасности в сфере пенсионного обеспечения и многое другое.

В заключение можно отметить следующее.

Сочетание накопительных и выплачиваемых пенсий, развитой сети социального обеспечения для пенсионеров, а также осуществление пенсионного надзора за деятельностью НПФ может повысить доверие граждан и качественно улучшить условия выхода на пенсию. Регулирование пенсионных сборов и, соответственно, пенсионных накоплений с расходами на их управление НПФ требует полного раскрытия информации, а также правил ценообразования и принимаемых решений. Кроме того, годовую динамику структуры активов

\footnotetext{
1 К понесенным затратам можно отнести инвестиционные сборы, вознаграждение за результат инвестирования, в которое входят плата за управление инвестициями (вычитается из стоимости инвестиций); входные и выходные сборы и расходы, оплата комиссионных при покупке или продаже акций; ежегодная плата и расходы по управлению фондом; торговые расходы и гербовый сбор, плата за производительность или исполнение инвестиционного договора (взимается некоторыми фондами сверх обычной годовой суммы); плата за совет финансовому консультанту (сумма определяется индивидуально) и многое др.
} 
НПФ необходимо раскрывать и размещать в открытом доступе по результатам проведенных ежегодных аудиторских проверок. Механизм правового регулирования наступления юридической ответственности (и гражданской правовой ответственности в частности) за необоснованную рисковую инвестиционную деятельность ПФ, НПФ, приведшую к уменьшению стоимости активов пенсионных фондов или к их банкротству, должен быть установлен законодательством государства. Он может включать как солидарную, так и субсидиарную ответственность участников правоотношений, включая ответственность государства. Автор понимает, что некоторые тезисы могут вызвать дискуссию, однако только в споре рождается истина.

\section{Список литературы}

Ткаченко А.А. 2019. Станут ли российские пенсионеры богаче? - Власть. T. 27. № 1. C. 29-41.

ESENOVA Valentina Petrovna, Cand.Sci. (Legal), Associate Professor; Associate Professor of the Chair of Law, North-Western Institute of Management - branch of Russian Presidential Academy of National Economy and Public Administration (RANEPA) (57/43 Sredniy Ave, V.O., St. Petersburg, Russia, 199178; VEsenova@gmail.com)

\section{PENSION PROVISION OF CITIZENS: THE PROBLEMS OF REFORM}

Abstract. The article reviewed the different aspects of reformation of pension provision, which have to be considered in order to provide the legal regulation and to find the right ways to resolve the problems of provision of pensions. The most crucial problems are the safety and increase of pensions during making the payment in the pension fund; effective administration of these payments and reduction of unnecessary expenses; formation of the new supervisory authority, ensuring a decent life for pensioners; formation of the legal liability for improper pension management, its reduction or depreciation.

Keywords: Pension Fund of Russia, pensioner, pension savings, management of pension fund, risk of safety of pension savings, legal liability 